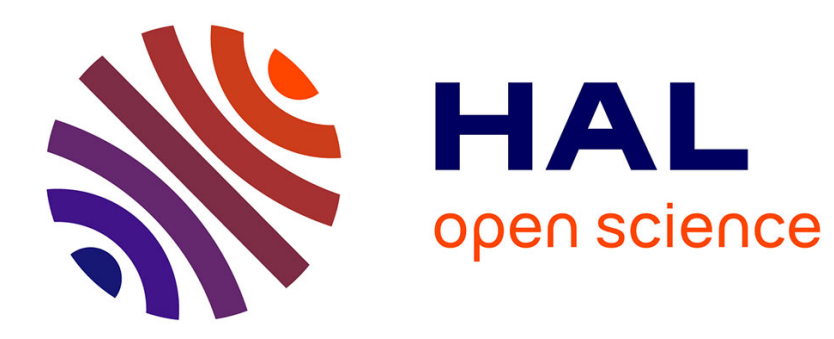

\title{
Telemedicine trends and challenges: a technology management perspective
}

John Puentes, Rajeev K Bali, Nilmini Wickramasinghe, Raouf Ng Naguib

\section{To cite this version:}

John Puentes, Rajeev K Bali, Nilmini Wickramasinghe, Raouf Ng Naguib. Telemedicine trends and challenges: a technology management perspective. International journal of biomedical engineering and technology, 2007, 1 (1), pp.59 - 72. 10.1504/IJBET.2007.014137 . hal-02179623

\section{HAL Id: hal-02179623 \\ https://hal.science/hal-02179623}

Submitted on 8 Jun 2021

HAL is a multi-disciplinary open access archive for the deposit and dissemination of scientific research documents, whether they are published or not. The documents may come from teaching and research institutions in France or abroad, or from public or private research centers.
L'archive ouverte pluridisciplinaire HAL, est destinée au dépôt et à la diffusion de documents scientifiques de niveau recherche, publiés ou non, émanant des établissements d'enseignement et de recherche français ou étrangers, des laboratoires publics ou privés. 


\title{
Telemedicine trends and challenges: a technology management perspective
}

\section{J. Puentes}

GET-ENST Bretagne,

Département Image et Traitement de l'Information,

Brest, France

INSERM U650,

Laboratoire de Traitement de l'Information Médicale,

Brest, France

\section{R.K. Bali}

Knowledge Management for Healthcare (KMH) Research Subgroup,

Biomedical Computing and Engineering Technologies Applied

Research Group (BIOCORE), Coventry University, Coventry, UK

\section{N. Wickramasinghe*}

Center for the Management of Medical Technology (CMMT), Stuart School of Business, Illinois Institute of Technology, 565 West Adams Street Ste 406, CHICAGO IL 60661, USA

E-mail: nilmini@stuart.iit.edu

${ }^{*}$ Corresponding author

\section{R.N.G. Naguib}

Biomedical Computing and Engineering Technologies Applied Research Group (BIOCORE),

Coventry University, Coventry, UK

\begin{abstract}
After four generations of varied applications, telemedicine now finds itself at a crossroads. Validated concepts have integrated the available technology to handle the basic system components, as well as data and information processing, in multiple manners. Medical data exchange has been tested as a result. Among the multiple technology evolutions that could be identified as significant trends we have selected four - wireless broadband, non-invasive sensors, emerging multimedia standards, and open source software - which are likely to have an impact on the current telemedicine progression, at the functional and economic levels. What follows is a description of each technology's main characteristics.
\end{abstract}


Keywords: telemedicine; wireless; healthcare; sensors; open source software; multimedia.

Reference to this paper should be made as follows: Puentes, J., Bali, R.K., Wickramasinghe, N. and Naguib, R.N.G. (2007) 'Telemedicine trends and challenges: a technology management perspective', Int. J. Biomedical Engineering and Technology, Vol. 1, No. 1, pp.59-72.

Biographical notes: J. Puentes holds an Electronics Engineering Degree, an MSc of Image Processing and Artificial Intelligence, and a PhD in Signal Processing and Telecommunications. He worked as engineer, consultant and project manager for biomedical and telecommunications companies, before moving to the Image and Information Processing Department at GET École Nationale Supérieure des Télécommunications de Bretagne, where he is assistant professor and associate researcher of the French Institute of Health and Medical Research. He is an invited associate editor and reviewer for several international journals, conferences and organisations. His primary research interests are medical practice support systems, image indexing, and telemedicine.

R.K. Bali is currently a reader at Coventry University, UK. He is the leader of the Knowledge Management for Healthcare research subgroup which works under the Biomedical Computing and Engineering Technologies (BIOCORE) Applied Research Group. He is an invited reviewer for several journals, conferences and organisations. His primary research interests are in health-care knowledge management, clinical governance, e-health, change management, organisational behaviour and medical informatics. His past and current $\mathrm{KM}$ projects include ICTs and KM for organisational decision-making in healthcare organisations and using KM to increase uptake of NHS Breast Screening Programme

N. Wickramasinghe researches and teaches in several areas within information system. In addition, she specialises in the impacts of technologies on the healthcare industry and various aspects of medical informatics. She is well published in all these areas having written several books and over 50 refereed scholarly. She regularly presents her work throughout North America as well as in Europe and Australasia. Currently, she is the Associate Director of the IIT Centre for Management Medical Technology (CMMT) and an Associate Professor at the Stuart School of Business, IIT.

R.N.G. Naguib is a Professor of Biomedical Computing and Head of the Biomedical Computing Research Group (BIOCORE) at Coventry University. He has published over 200 journal and conference papers and reports in biomedical image processing and the applications of artificial intelligence and evolutionary computation in cancer research. He has also published a book on digital filtering, and co-edited a second book on the applications of artificial neural networks in cancer diagnosis, prognosis, and patient management, which is his main area of research interest. 


\section{Introduction}

By the end of the 19th century, when the telephone was becoming a means of communication, the idea of transmitting heart beat sounds via such media can be arbitrarily identified as the beginning of telemedicine. This pioneer generation also enabled the transmission of electrocardiogram signals using the telephone, and exploited the available radio communications to provide advice about medical emergencies on commercial ships. A second applications generation is commonly identified between the early 1950s and 1970s, characterised by the documented use of other technologies and scenarios like the Nebraska Psychiatric Institute closed-circuit TV to remotely follow-up some patients; the remote monitoring of spacecraft crew; the provision of health services at the Boston's Logan airport through a microwave connection with the Massachusetts general hospital; and the medical exchanges of small isolated towns in Alaska and Canada with city hospitals, using satellites. From the early 1970s to the 1990s, natural disaster scenarios, particularly the Armenian and Mexican earthquakes allowed the testing of telemedicine disaster relief prototypes, by means of medical consultations from the affected zones to hospitals in the USA. The fourth generation appears with internet deployment in the mid 1990s, providing an unexpected applications spectrum (Yamamoto et al., 1996; Horsch and Balbach, 1999; Sacile et al., 1999; Lovell et al., 2001; Williams et al., 2001).

Simultaneously, behind the technology evolution, various definitions have emerged which explain what telemedicine is about (Holzer, 1974; Bashshur et al., 2000; Tulu et al., 2005), without reaching a global conceptual agreement, even though the essence of each definition is somewhat analogous. A relative confusion has been generated thereafter, by the use of similar terms, to name what is assumed to be different application domains. Far from this controversy, our understanding of the subject concerns telecommunication and information technologies application, to enable medical practice when distance between actors will otherwise impede its accomplishment. Hence, access to medical services in this particular context is provided to medical professionals and patients, along with the processing of the exchanged medical data, independently of the medical data type, its purpose, or the distant interaction features.

Following analog to digital technology transition, the question about what to assess on a telemedicine system (Tohme and Olsson, 1996), has received varied foci on technology feasibility and performance, medical perception of the developed prototypes and applications, clinical impact, organisational effect, healthcare policy, security implications, and so on. Independently of the assessment criteria, the core implementation idea has been to test medical data exchange, using a particular technology set up in a previously defined scenario. For multiple reasons and despite the assessment type, promising results have been rarely transformed into routinely exploited systems, generating a very slow transfer rate from laboratory experiences to widely used products. However, current technology trends may have a more encouraging outcome.

This paper proposes to examine how four current technology trends - wireless broadband, non-invasive sensors, emerging multimedia standards and open source software - could affect telemedicine's progress, and how their development may improve the gap between urban and rural telemedicine, the ergonomics of sensing devices and the cost of implemented prototypes. The rest of the paper is organised as follows. Section 2 presents the telemedicine axes which may be affected by the discussed technology trends. Section 3 describes the selected current technology trends before 
presenting in Section 4 what we consider are significant related challenges to be examined. In Section 5 we discuss the proposed perspective and state the conclusion of our work.

\section{Perspective context}

Technology breakthroughs have not dramatically affected or modified telemedicine systems, for instance, to improve their clinical practice integration, or facilitate their wide utilisation at different medical practice levels. Multiple economical, professional, societal and political factors affect telemedicine's potential in complex manners. Therefore, our particular vision focuses on the impact that the expanding available technology is likely to have on the characteristics of future telemedicine systems, at the functional and economic levels, without taking into account the other factors. Expected evolutions concern significant progress in the quality and accessibility of the basic system building modules. Particularly, some of the necessary advancements are related to the gap between urban and rural telemedicine, the ergonomics of sensing devices and the cost of implemented prototypes.

Different sophistication scales are found in current telemedicine systems. The initial goal of providing medical services to underserved zones is being increasingly sought in industrialised countries' urban scenarios, and between urban hospitals across national borders (Moore, 2002). Such development can be explained in part by the pursuit of reduced costs, profit increase and efficiency enhancement to improve urban patients' access to healthcare, and the growing demand for home healthcare. While urban telemedicine progresses using state of the art technology, rural telemedicine stays behind. In this sense some of the discussed technology trends could have a remarkable effect on rural telemedicine expansion.

Continuous global ambulatory monitoring, particularly required in the case of chronic diseases, the health status surveillance of aged people, and patients in rehabilitation, is becoming both feasible and affordable (Koch, 2006). However, most of the employed equipment measures and transmits single vital sign parameters, requiring a cumbersome collection of sensing, storing and transmission devices, without any specific associated information and decision support systems. Consequently, there is a fundamental need for wearable systems, integrating multiple sensors, capable of performing intelligent processing and generating alarms to support medical decision, allowing easy interaction at any moment with the healthcare provider (Lymberis, 2003). These systems are necessary to provide friendly home monitoring, eventually leading to pervasive healthcare (Maglaveras et al., 2005).

On the other hand, telemedicine is a multidimensional application domain, whose development has been technology-driven (Paul et al., 1999); users need to constantly adjust their requirements to technology constraints. In general, the modules used in the assembled solutions have not been originally conceived for telemedicine, but for other domains (Brender et al., 2000; Lee et al., 2003; Parker et al., 2005). As a consequence, the availability of affordable technology has frequently lead us to assume that almost any device can be integrated into a telemedicine platform, forcing final users to accept whatever is proposed as a solution, just because it seems technologically sound. Cheaper, open and more accessible technologies could alleviate some of those difficulties. 


\section{Main current technology trends}

Technological development is far from a simple linear progression (Colburn, 2005). As in any other similar field, telemedicine's accomplishments are made out of separate technologies being integrated in multiple manners. Regardless of the technical advances, any telemedicine system is constructed with four basic modules: data transmission, content, terminals and instruments, data and information processing. Several technology examples for each one are schematically summarised in Table 1, giving a notion of the varied and still growing offer.

Table 1 Telemedicine basic technology modules

\begin{tabular}{ll}
\hline Module & Examples \\
\hline Data transmission & $\begin{array}{l}\text { Telephone, GPRS-EDGE, 2G, 3G, DSL, ISDN, ATM, leased lines, } \\
\text { optical network }\end{array}$ \\
Content & $\begin{array}{l}\text { Voice, videoconference, 2D and 3D gray level and color images, grey } \\
\text { level and colour videos, physiological signals, physiological values, } \\
\text { haptic signals }\end{array}$ \\
& $\begin{array}{l}\text { Television, personal computer, PDA, mobile phone, scopes } \\
\text { (e.g., dermascope, otoscope, stethoscope, opthalmoscope), scanner, }\end{array}$ \\
Terminals and & $\begin{array}{l}\text { photo camera, video camera } \\
\text { instruments }\end{array}$ \\
$\begin{array}{l}\text { File exchange, data base construction and maintenance, security, } \\
\text { interactivity, signal and image processing for diagnosis support, } \\
\text { processing }\end{array}$ & \begin{tabular}{l} 
augmented and virtual reality \\
\hline
\end{tabular}
\end{tabular}

From among the multiple technology evolutions that could be identified as significant trends we have selected four which are likely to influence the way in which either one or two of the four basic modules will be approached in the near future. These current technology trends are: wireless broadband, non-invasive sensors, emerging multimedia standards and open source software. A general description is presented in the next paragraphs.

\subsection{Wireless broadband}

Available data transmission infrastructure varies from conventional telephone lines to sophisticated optical networks (Al-Qirim, 2005; von Lubitz et al., 2006). Table 2 lists the estimated bandwidths for some of the main technologies. Even though most of the highest bit rates indicated for each technology can be hardly obtained under practical conditions, the average values could serve as reference for the purpose of comparison. Additionally, it is necessary to consider that, as the estimated bit rate increases so does the price, limiting the potential use of the technology in a telemedicine scenario. On the other hand, only some of the transmission technologies are able to seamlessly transmit all types of content. Therefore, the possibility of connecting distant points using wireless broadband, capable of transmitting a considerable percentage of content types appears like a reasonable compromise to improve telemedicine services. 
Table 2 Estimated data transmission bit rates

\begin{tabular}{ll}
\hline Technology & Estimated bit rate $(\mathrm{bit} / \mathrm{s})$ \\
\hline Telephone & $14.4-56 \mathrm{k}$ \\
GPRS - EDGE & $30-80 \mathrm{k}, 160-236.8 \mathrm{k}$ \\
$2 \mathrm{G}$ & $128-256 \mathrm{k}$ \\
$3 \mathrm{G}$ & $144-1 \mathrm{M}$ \\
DSL & $64-1.544 \mathrm{M}$ \\
ISDN & $144-2 \mathrm{M}$ \\
ATM & $45-155 \mathrm{M}$ \\
Leased lines & $154-274.17 \mathrm{M}$ \\
Optical network & $51.84-2.84 \mathrm{G}$ \\
\hline
\end{tabular}

In this sense, World Interoperability for Microwave Access (WiMAX) proposes a point-to-multipoint, broadband wireless networking for internet access (Fijnvandraat and Bouwman, 2006). It has been conceived to transport data over frequency ranges from $2 \mathrm{GHz}$ to $66 \mathrm{GHz}$, providing single-channel data rates up to $75 \mathrm{Mbit} / \mathrm{s}$, through a potential transmission distance of $50 \mathrm{~km}$ without line of sight, keeping the data bit rate. Compared to the original Wireless Fidelity (WiFi) technology, both range of coverage and bit rate will improve significantly (Vaughan-Nichols, 2004). Data transmission is expected to be highly scalable, given that it will be possible to add transmission channels when bandwidth increment is required, along with the planned flexibility, to use different frequencies depending on specific transmission characteristics. Additionally, a quality of service implementation is expected for the frequency range from $5 \mathrm{GHz}$ to $6 \mathrm{GHz}$, in order to prioritise transmissions according to the traffic type.

Most of the existing broadband technologies are proprietary, entailing higher infrastructure deployment costs compared to standardised wireless technologies. With a large amount of rural zones having reduced profit potential for service providers, a standardised technology like WiMAX could provide a less expensive, interoperable and easier to build, data transportation broadband solution for those areas. Telemedicine services could, therefore, be expanded through the installation of short and medium range links in non deserved regions, compatible with the backbones of established vendors.

\subsection{Non-invasive sensors}

Remote health monitoring is quickly being developed by the use of micro and nano sensors that make non-invasive and comfortable measurements by means of wearable and external sensors possible. Thermal, electrical, geometrical and mechanical parameters, among others, can be measured from the skin by means of non-invasive sensors of reduced size. Table 3 lists the main kinds of sensors and their applications (Axisa et al., 2005). 
Table 3 Examples of non-invasive sensors and the physiological phenomena they allow assessing

\begin{tabular}{ll}
\hline Sensor & Assessed physiological phenomena \\
\hline Thermal & $\begin{array}{l}\text { Skin blood flow, skin hydration, skin thermal conductance, skin infection, } \\
\text { thermal comfort, metabolism, fever, muscular activity, autonomic nervous } \\
\text { system activity and respiration rate }\end{array}$ \\
Electrical & $\begin{array}{l}\text { Electrocardiogram, heart rate, autonomic nervous system activity, } \\
\text { electromyography, electrocardiogram, vigilance and stress level }\end{array}$ \\
Geometrical & $\begin{array}{l}\text { Respiration rate and amplitude, heart rate, blood pressure, detection of falls, } \\
\text { body position, mobility, monitoring of daily activities, circadian rhythm, sore } \\
\text { and hard point detection }\end{array}$ \\
Mechanical & $\begin{array}{l}\text { Interface pressure measurement in living tissues (skin, subcutaneous tissue, } \\
\text { blood vessels and bone) }\end{array}$ \\
\hline
\end{tabular}

In addition to their small size and precision, these sensors can communicate with other devices, are capable of measurements with increased signal bandwidth, and some of them have taken unexpected forms, like fabric. Considering that cloths are in contact with around $90 \%$ of the skin surface, piezoresistive and conductive materials in the form of fibres and yarns are knitted into a multifunctional sensing fabric, capable for instance, of measuring electrocardiogram, respiration, body activity and temperature. Their feasibility in the form of smart clothes has been demonstrated (Axisa et al., 2005, Paradiso et al., 2005), validating expected advantages like discretion, robustness, accurate sensor position in the proper location, and easiness of use. There are two main kinds of smart clothing: one uses sensors located in close proximity to the skin (e.g., temperature, skin blood flow, electrocardiogram, muscle activity, respiration) and inversely, the other uses different sensors that are not directly in contact with the skin (e.g., solar cells, micro transmitters, wrist device, phone, data storage device). Other sensors are neither in contact with the skin, nor placed in clothing pockets, but located around different patient's activity environments, like in the smart home concept (Demongeot et al., 2002). All these sensors require major changes in the distant monitoring system concept and associated data processing, beyond passive patient surveillance, according to the subject daily activities.

\subsection{Emerging multimedia standards}

Medical data embody a strong, inherent multimedia nature (Dionisio et al., 1996; Delamarre et al., 1999; Guerri et al., 2000). Media objects are generated in the form of signals, still images, image sequences, voice recordings, exam results and written diagnostic reports, among others. As a consequence, any telemedicine setup is expected to integrate several functionalities that use multimedia data. However, it is difficult to decide which technologies to rely on when implementing telemedicine applications, given the abundant proprietary technologies that compete with international and de facto standards, raising numerous integration and interoperability issues. In order to avoid them as much as possible, the interest of standards definition is to provide a common action ground between industrial initiatives, research results and user preferences, stabilising technology and promoting markets growth. Some standards have been created for medical information systems (e.g., HL7, DICOM), but none specifically for telemedicine, 
where, as well, there is as well, a genuine need to ease and strengthen systems integration.

Several emerging multimedia standards for data compression and manipulation like JPEG 2000 (Christopoulos et al., 2000) and MPEG-4 (Puri and Chen, 2000) have been developed in recent years. Even if their original application domains are entertainment, audio-visual production, commercial portals and education, they are also suitable for medical applications (Puentes and Roux, 2000). JPEG 2000 addresses the need for greater image compression with enhanced flexibility and efficient interoperability. Based on wavelets, among its interesting features, we find: superior low bit-rate performance useful for network image transmission; compression and decompression of images with various dynamic ranges for each component; higher lossless compression ratio to preserve data integrity; image reconstruction with different spatial and frequency resolutions depending on the application; decompression of arbitrary shaped user defined regions of interest, with less distortion than the rest of the image; robustness to bit errors in wireless communication channels; content-based description in XML (eXtensible Markup Language); theoretical processed image sizes vary from $32 \times 32$ to $10 \mathrm{k} \times 10 \mathrm{k}$ pixels, with as much as 16.384 components, a pixel precision up to 38 bits/component; and the possibility to integrate XML formatted metadata with the coded image, encapsulated in one file. These features have been applied, for example, to implement a telepathology specialised patient record (Montesinos and Puentes, 2003), later adapted to enable secured nuclear medicine second opinion consultations (Puentes et al., 2006).

The MPEG-4 standard defines multimedia systems for interoperable communication of complex scenes containing audio, video, and synthetic graphics material. It has been conceived to enhance reusability and flexibility of multimedia content, transparent information flow in heterogeneous networks and higher levels of interaction between end users and multimedia content. MPEG-4 offers a broad variety of tools and resources, which can also be applied to handle medical information, like multimedia data acquired for diagnostic purposes. It characterises different media as independent objects, coded in elementary streams. Separated streams are used for objects and their descriptions. The grouping of these objects by means of scene and object description information is called composition. Apart from synthetic and natural 2D and 3D images, other objects are: formatted text documents, natural or synthetic video, natural or synthetic sound, and compound objects. In addition to a flexible content representation and user interactivity with the different objects, the standard proposes adaptable data storage and transportation. Different profiles are created for diverse application environments, choosing subsets of the standard specifications: visual, audio, graphics, and scene graph, profiles. Preliminary studies have been carried out to validate medical multimedia contents delivery using MPEG-4 (Yamakawa et al., 2004).

\subsection{Open source software}

Dependency on proprietary software vendors has hindered telemedicine systems development, because the provided applications are not flexible and cannot be maintained by their owners, if necessary. Moreover, dissemination of telemedicine applications highly depends on the availability of open applications architectures that can be replicated at low cost (Forslund et al., 2004). Currently, the open source software initiative aims to make software sources as widely available as possible. These kind of applications are being developed by both companies and individual programmers, with a 
particular emphasis on collaborative development, facilitating rapid software evolution of assumed equivalent or better quality compared to similar proprietary developments.

Certain rules, in the form of a license, have to be respected though, in order to copy, modify, and redistribute open source code (de Laat, 2005). The license stipulates the conditions of the free code availability, which should include: free redistribution of the source code and its compiled form, allowing modifications and derived works that can be distributed under the same terms of the original software license; possibility of distribution restrictions if the modified code distribution is not explicitly authorised by the license; authorisation or banning of derived work from having the same name and version number as the original source code; no access discrimination against persons or groups; impossibility of restricting the distributed code use to a specific field of research, business, or product; and technology neutrality of the license. Additionally, the application of a given license does not imply that new licenses should be created between engaged parties.

Some popular open source software distributions that can be used for content coding, terminals and instruments data manipulation tasks, as well as data and information processing in telemedicine applications are: Linux (operating system), Java, GCC and Tcl/Tk (application development), Apache (web server), MySQL (relational data base), VTK (visualisation tools), ITK (image segmentation and registration), PHP (website creation), Audacity (audio editor), GIMP and ImageMagik (image processing), VLC (video coding and decoding), Mozilla Firefox (web browser), Mozilla Thunderbird (e-mail), among others. Initially applied to implement a small number of application components, open source software is being used for the whole integrated application conception, like cardiac images exchange (Marcheschi et al., 2003), syndromic surveillance (Forslund et al., 2004) and disease coding (Shu et al., 2004).

\section{Challenges}

Already known telemedicine challenges (Solaiman et al., 2001) turn out to be more complex in the presence of the identified current technology trends. This section examines some of the challenges those trends face before they can be reliably adopted to develop integrated telemedicine solutions.

\subsection{Wireless broadband}

Some analysts consider that WiMAX technical characteristics are unrealistic (Conti, 2005), given that so far the experimental measured cell radius has been between $7 \mathrm{~km}$ and $10 \mathrm{~km}$, far from the expected $50 \mathrm{~km}$. Furthermore, the targeted radio spectrum contains licensed and unlicensed bands, which are different from one country to another. Security using 56-bit data encryption standard keys may be also an issue, considering recent advances that show how 128-bit hash functions can be broken (Wang and $\mathrm{Yu}, 2005)$, even if it does not mean yet that unauthorised users will be capable of doing it. Certainly, it is not clear if the constructed systems will progressively evolve towards the expected theoretical specifications, depending on market dynamism. Besides, the struggle with proprietary established broadband technologies will depend on lower prices and the expected interoperability performance. 


\subsection{Non-invasive sensors}

Regardless of the multiple improvements offered by the new non-invasive sensors, there are issues to resolve concerning the operation modes understanding, the communication bit rates, the transmitted data characteristics, the type of supported medical decisions, and the current lack of information support systems, capable of providing adequate alarms and a reasonable level of system personalisation. Moreover, other questions like comfortable and easy to use interfaces, low power devices and off-line processing capabilities need to be addressed.

\subsection{Emerging multimedia standards}

When used in telemedicine, emerging multimedia standards make it necessary to analyse their suitability to the different application scenarios. Various profiles have to be examined in detail for compliance with information quality, and simplicity of use requirements. This also implies that in conditions of limited infrastructure for data transportation, storage and processing, as is frequently the case in rural telemedicine, the standards performance must be thoroughly evaluated in advance, to avoid distant diagnosis services users' discouragement, because of technology inadequacy. Furthermore, it is difficult to precisely determine the optimal compression rate when dealing with data compression, given the specialists intra and inter image quality perception variability.

\subsection{Open source software}

Telemedicine's specific requirements are only partially met by open source software. The available code is generally inspired by existing proprietary applications, frequently requiring laborious tailoring to attain project requirements. Others, for example XML, designed by an interest group, are widely used, but work is still in progress to provide interoperable settings allowing multiple systems to work together in a seamless manner. Otherwise, the collective production model force is weakened by the difficulty to actually verify that only the most performing approaches are integrated into each software version. In addition to poor code often developed, the rather deficient documentation of multiple projects demands an unnecessary time consuming effort to understand the code for those who have not contributed to developing it.

\section{Discussion and conclusion}

Overwhelming technology production is constantly increasing the available data transmission, content, terminals and instruments, data and information processing resources. Given that technology will keep changing, many prototype implementations will be carried out, almost certainly adopting the same scheme described in Section 1. Even if key issues like project conducting methodology, workflow analysis, and service models are not shaped by the integration of the identified technology trends, the gap between urban and rural telemedicine, the ergonomics of sensing devices and the cost of implemented prototypes could be certainly affected in a practical manner. In any case, 
applications should be attached to the experts' formal and informal daily communication routines (Lehoux et al., 2002).

State of the art technologies have been commonly used to test and validate telemedicine concepts. Nevertheless, such infrastructure does not usually exist in rural areas. As a consequence, urban and rural telemedicine are progressing in different directions, encompassing respectively, quite specialised and general services. It is important to note that health services export across international borders, as part of the health services globalisation international agreements (Chanda, 2001), strongly accentuates this urban-rural contrast. As a consequence, urban hospitals in big cities of industrialised countries are outsourcing certain services, like image diagnosis or report transcriptions, to qualified specialists in less industrialised countries urban hospitals.

The identified current technology trends are likely to influence urban and rural scenarios in different ways. Wireless broadband seems more appropriate for rural setups, assuming that prices will be affordable in the near future. Its potential contribution resides in the fact that towns within the antenna's range could eventually have an optimised IP connection. WiMAX capacity to prioritise traffic with a quality of service scheme is, on the contrary, a required characteristic for both urban and rural applications (Shortlife et al., 2000). A similar contribution could be expected from open source software because of its potential to reduce telemedicine systems' development cost, as long as the implemented systems target specific applications, with well documented software and requirements. Another area where such a role is expected concerns data and information processing, taking into consideration that once exchanged, medical data need to be processed for multiple purposes: patient record handling and management, medical practice support, sanitary vigilance, clinical research, etc. Multiple generic open source libraries are currently available, requiring a demanding adaptation. Otherwise, emerging multimedia standards are still evolving, but their adequacy for telemedicine applications can be examined and validated. Finally, urban telemedicine could benefit from fabric-easy-to-use sensing elements, for continuous home remote monitoring.

The proliferation of information and communication technologies in supporting highly specialised tasks and services has made it increasingly important to understand the factors essential to technology acceptance (Chau and $\mathrm{Hu}$, 2002). Addressing technological barriers is a necessary but not sufficient condition if telemedicine is to fulfil its promise (Paul et al., 1999). Only after such barriers are addressed can other barriers such as professional, legal and financial come to the fore. Studies on the mismatch between the sophistication of the technology and end-user requirements for clinical activities and patient confidentiality and privacy issues confirm that such issues can be supported as barriers, but how they impacted on telemedicine utilisation was different from expectations (Paul et al., 1999).

Studies concerning teledermatology have debated issues on the observed movements in professional boundaries, how these movements were possible, why they took place, and the role that the technology played in this process (Lawton and Timmons, 2006).

Clearly, the exponentially growing availability of numerous and varied technology solutions is both challenging and exciting for the future of telemedicine. We close by urging for more research in this area that is indisputably playing a larger and larger role in global healthcare delivery. 


\section{References}

Al-Qirim, N. (2005) 'Telemedicine: building knowledge-based tele-health capability in New Zealand', in Wickramasinghe, N., Gupta, J. and Sharma, S. (Eds.): Creating Knowledge Based Healthcare Organisations, Idea Group Publishing, Hershey, pp.193-207.

Axisa, F., Schmitt, P.M., Gehin, C., Delhomme, G., McAdams, E. and Dittmar, A. (2005) 'Flexible technologies and smart clothing for citizen medicine, home healthcare, and disease prevention', IEEE Transactions on Information Technology in Biomedicine, Vol. 9, No. 3, pp.325-336.

Bashshur, R.L., Readon, T.G. and Shannon, G.W. (2000) 'Telemedcine: a new health care delivery system', Annual Review of Public Health, Vol. 21, pp.613-637.

Brender, J., Nøhr, C. and McNair, P. (2000) 'Research needs and priorities in health informatics', International Journal of Medical Informatics, Vols. 58-59, No. 1, pp.257-289.

Chanda, R. (2001) 'Trade in health services', Commission on Macroeconomics and Health, Working Paper Series, WG4, Vol. 5, pp.1-117.

Chau, P.Y.K. and Hu, P.J-H. (2002) 'Investigating healthcare professionals' decisions to accept telemedicine technology: an empirical test of competing theories', Information and Management, Vol. 39, No. 4, pp.297-311.

Christopoulos, C., Skodras, A. and Ebrahimi, T. (2000) 'The JPEG 2000 still image coding system: an overview', IEEE Transactions on Consumer Electronics, Vol. 46, No. 4, pp.1103-1127.

Colburn, R. (2005) The Marconi Century, Marconi Instruments, IEEE History Centre, New York.

Conti, J.P. (2005) 'The long road to WiMAX', IEE Review, Vol. 51, No. 10, pp.38-42.

de Laat, P.B. (2005) 'Copyright or copyleft?: an analysis of property regimes for software development', Research Policy, Vol. 34, No.10, pp.1511-1532.

Delamarre, P., Le Beux, P., Bedossa, M., LeBreton, H., Baskurt, A., Croci, S., Decaix, M. and Pony, J.C. (1999) 'CARDIOMEDIA: A Communicable Multimedia Medical Record on Intranet and Digital Optical Memory Card', International Journal of Medical Informatics, Vol. 55, No. 3, pp.211-222.

Demongeot, J., Virone, G., Duchêne, F., Benchetrit, G., Hervé, T., Noury, N. and Rialle, V. (2002) Multi-Sensors Acquisition, Data Fusion, Knowledge Mining and Alarm Triggering in Health Smart Homes for Elderly People, C.R. Biologiques, Vol. 325, pp.673-682.

Dionisio, J.D., Cárdenas, A.F., Taira, R.K., Aberle, D.R., Chu, W.W., McNitt-Gray, M.F., Goldin, J. and Lufkin, R.B. (1996) 'A unified timeline model and user interface for multimedia medical databases', Computerized Medical Imaging and Graphics, Vol. 20, No. 4, pp.333-346.

Fijnvandraat, M. and Bouwman, H. (2006) 'Flexibility and broadband evolution', Telecommunications Policy, Vol. 30, Nos. 8-9, pp.424-444.

Forslund, D.W., Joyce, E.L., Burr, T., Picard, R., Wokoun, D., Umland, E., Brillman, J.C., Froman, P. and Koster, F. (2004) 'Setting standards for improved syndromic surveillance', IEEE Engineering in Medicine and Biology Magazine, Vol. 23, No. 1, pp.65-70.

Guerri, J.C., Esteve, M., Palau, C., Monfort., M. and Sarti, M.A. (2000) 'A software tool to acquire, synchronise and playback multimedia data: an application in kinesiology', Computer Methods and Programs in Biomedicine, Vol. 62, No. 1, pp.51-58.

Holzer, W.H. (1974) 'Telemedicine: new application of communications', IEEE Transactions on Communications, Vol. 22, No. 5, pp.685-688.

Horsch, A. and Balbach, T. (1999) 'Telemedical information systems', IEEE Transactions on Information Technology in Biomedicine, Vol. 3, No. 3, pp.166-175.

Koch, S. (2006) 'Home telehealth - current state and future trends', International Journal of Medical Informatics, Vol. 75, No. 8, pp.565-576.

Lawton, S. and Timmons, S. (2006) 'The relationship between technology and changing professional roles in health care: a case-study in teledermatology', Studies in Health Technology and Informatics, Vol. 122, pp.669-671. 
Lee, S., Broderick, T.J., Haynes, J., Bagwell, C., Doarn, C.R. and Merrell, R.C. (2003) 'The role of low-bandwidth telemedicine in surgical prescreening', Journal of Pediatric Surgery, Vol. 38, No. 9, pp.1281-1283.

Lehoux, P., Sicotte, C., Denis, J.L., Berg, M. and Lacroix, A. (2002) 'The theory of use behind telemedicine: how compatible with physicians' clinical routines?', Social Science and Medicine, Vol. 54, pp.889-904.

Lovell, N.H., Magrabi, F., Celler, B.G., Huynh, K. and Garsden, H. (2001) 'Web-based acquisition, storage, and retrieval of biomedical signals', IEEE Engineering in Medicine and Biology Magazine, Vol. 20, No. 3, pp.38-44.

Lymberis, A. (2003) 'Smart wearables for remote health monitoring, from prevention to rehabilitation: current R\&D, future challenges', Proc. 4th IEEE EMBS Special Topic Conference on Information Technology Applications in Biomedicine, Birmingham, UK, pp.272-275.

Maglaveras, N., Chouvarda, I., Koutkias, V.G., Gogou, G., Lekka, I. et al. (2005) 'The citizen health system (CHS): a modular medical contact centre providing quality telemedicine services', IEEE Transactions on Information Technology in Biomedicine, Vol. 9, No. 3, pp.353-362.

Marcheschi, P., Ferdeghini, E.M., Mazzarisi, A. and Benassi, A. (2003) 'An open-source based application for integration and sharing of multi-modal cardiac image data in a heterogeneous environment', Computers in Cardiology, Thessaloniki, Greece, Vol. 30, pp.367-370.

Montesinos, L. and Puentes, J. (2003) 'Specialised telepathology electronic patient record based on JPEG 2000', Proc. 4th IEEE EMBS Special Topic Conference on Information Technology Applications in Biomedicine, Birmingham, UK, pp.110-113.

Moore, S.K. (2002) 'Extending healthcare's reach', IEEE Spectrum, Vol. 31, No. 1, pp.66-71.

Paradiso, R., Loriga, G. and Taccini, N. (2005) 'A wearable health care system based on knitted integrated sensors', IEEE Transactions on Information Technology in Biomedicine, Vol. 9, No. 3, pp.337-344.

Parker, D.R., Demiris, G. and Porock, D. (2005) 'The usability of videophones for seniors and hospice providers: a brief report of two studies', Computers in Biology and Medicine, Vol. 35, No. 9, pp.782-790.

Paul, D.L., Pearlson, K.E. and McDaniel Jr., R.R. (1999) 'Assessing technological barriers to telemedicine: technology-management implications', IEEE Transactions on Engineering Management, Vol. 46, No. 3, pp.279-288.

Puentes, J. and Roux, C. (2000) 'Multimedia technologies in medicine: the role of emerging standards', Proc. 3rd IEEE EMBS Special Topic Conference on Information Technology Applications in Biomedicine, Arlington, USA, pp.4-9.

Puentes, J., Coatrieux, G. and Lecornu, L. (2006) 'Secured electronic patient records exploitation', in Bali, R.K. and Dwivedi, A. (Eds.): Healthcare Knowledge Management: Issues, Advances and Successes, Springer-Verlag, New York, pp.162-178.

Puri, A. and Chen, T. (2000) Multimedia Systems, Standards and Networks, Marcel Dekker, New York.

Sacile, R., Ruggiero, C., Lombardo, C., Nicolo, G., Wolf, G., Rudolph, B. and Petersen, I. (1999) 'Collaborative diagnosis over the internet: a working experience', IEEE Internet Computing, Vol. 3, No. 6, pp.29-37.

Shortliffe, E., Altman, R.B., Brennan, P.F., Davie, B., Detmer, W.M., Florance, V., Friede, A., Frisse, M., Glaser, J., Huffman, J., Kohane, I., Landwehr, C. E., Masys, D.R., Sisk, J.E. and Von Eicken, T. (2000) Networking Health: Prescriptions for the Internet, Computer Science and Telecommunications Board, The National Academies, Washington DC.

Shu, J., Clifford, G.D., Long, W.J., Moody, G.B., Szolovits, P. and Mark, R.G. (2004) 'An opensource, interactive java-based system for rapid encoding of significant events in the ICU using the unified medical language system', Computers in Cardiology, Chicago, USA, Vol. 31, pp.197-200 
Solaiman, B., Cauvin, J.M., Puentes, J., Le Guillou, C., Brunet, G., Debon, R. and Roux, C. (2001) 'Enabling technology for telemedicine and telehealth', Proc. 23rd International Conference IEEE EMBS, Istanbul, Turkey, Vol. 4, pp.4113-4116.

Tohme, W.G. and Olsson, S. (1996) 'Developments and directions of technology assessment in telemedicine', Proc. 4th IEEE Image Management and Communications, Hawaii, USA, pp.79-85.

Tulu, B., Chatterjee, S. and Laxminarayan, S. (2005) 'A taxonomy of telemedicine efforts with respect to applications, infrastructure, delivery tools, type of setting and purpose', Proc. 38th IEEE International Conference on System Sciences, Hawaii, USA, pp.1-10.

Vaughan-Nichols, S.J. (2004) 'Achieving wireless broadband with wimax', IEEE Computer, Vol. 37, No. 6, pp.10-13.

von Lubitz, D., Wickramasinghe, N. and Yanovsky, G. (2006) 'Networkcentric healthcare operations: the telecommuniucations structure', International Journal of Networking and Virtual Organisations, Vol. 3, No. 1, pp.60-85.

Wang X. and $\mathrm{Yu}, \mathrm{H}$. (2005) 'How to break MD5 and other hash functions', in Cramer, R. (Ed.): Advances in Cryptology - Eurocrypt, Lecture Notes in Computer Science 3494, Springer-Verlag, New York, pp.19-35.

Williams, M.H., Venters, G. and Marwick, D. (2001) 'Developing a regional healthcare information network', IEEE Transactions on Information Technology in Biomedicine, Vol. 5, No. 2, pp.177-180.

Yamakawa, T., Toyabe, S., Cao, P. and Akazawa, K. (2004) 'Web-based delivery of medical multimedia contents using an MPEG-4 system', Computer Methods and Programs in Biomedicine, Vol. 75, pp.259-264.

Yamamoto, L.G., Elliott, P.R., Herman, M.I. and Abramo, T.J. (1996) 'Telemedicine using the internet', The American Journal of Emergency Medicine, Vol. 14, No. 4, pp.416-420. 